\title{
RE-THINGIFYING THE INTERNET OF THINGS
}

Jennifer Gabrys

In Sustainable Media: Critical Approaches to Media and Environment

Edited by Nicole Starosielski and Janet Walker (Routledge, 2016)

An increasing number of gadgets are now electronic, or fitted with microchips, and typically networked. The many claims made for the Internet of Things announce that computation is set to become ever more ubiquitous, where "things" equipped with radio frequency identification (RFID) tags and sensors will collect and circulate data for actuating responses through interoperable networks and so become "smart." The Internet of Things is at once heralded as a revolution in organizing our physical worlds as well as an unparalleled source of economic development. With the promised explosion of networked objects, electronics industries have turned to things, after so long fixing their attention on screens, software, and "cyberspace." No more does the distinction of virtual and physical retain its neat bifurcation, since what would have counted as virtual is coursing through and remaking the contours and functionalities of the physical. Things, within the Internet of Things, are the curious creatures to which I turn my attention in this chapter. What are these things in the Internet of Things and what are the characteristics of their emerging materialities? How, as newly electronicized objects, do they manifest distinct material and environmental effects? And how might an attention to these material and environmental effects provide an opportunity for generating new areas of environmental intervention in relation to sustainable media?

Media theory is now increasingly calling for an attention to the materiality of the digital. Where previous studies may have focused on the meaning or signification of media, or transfixed on screens as sites of cultural representation, materiality-based media studies are increasingly in development as key contributions to the field. Friedrich Kittler and Katherine Hayles have taken materiality as a topic of interest, noting that materialities are structuring conditions that inform the very possibilities of communication. ${ }^{1}$ However, these earlier studies typically have attended less to materiality as a social, environmental, or political concern, and more as a logistical, structuring, or informing condition. Alongside theorists like Lisa Parks and Matthew 
Fuller, I have argued for a consideration of what lies beyond the screen, of how hardware unfolds into wider ecologies of media devices, and of how electronic waste may evidence the complex ways in which media are material and environmental, despite our tendency to overlook these interconnected infrastructures, supports, and resources. $^{2}$

Materiality as a topic and research focus now pervades media studies, as much as an obligation and directive not to forget all that media rely upon. At the same time, but along different lines, a more material turn could be found within the industries of digital media as well. "Thingification" is an overtly material approach to the previously "virtual" concerns of digital media, and is an industry strategy that is meant to expand the reach, capacities, and economic growth of the Internet. Where at one time industry claims were made for the resource-free living that might be achieved through the growth of economies spurred through virtual technologies, this deliberate thingification instead makes the case for the ways in which computational logics may make any number of activities and practices within our everyday lives more efficient, sustainable, and safe. The material relations that are the proposed site of intervention by digital media industries are now less about the erasure or elision of material resources, and more about making materialities and environments smarter and more effective, while stretching resources further in the face of increasing scarcity and planetary pressures. ${ }^{3}$

This chapter then asks: What are these things within the Internet of Things and how do they influence, challenge, disrupt, or reroute discussions of materiality within media studies? What consequences do these things have for thinking about the environmental effects and relations generated through the Internet of Things? After first discussing the things and thingification that the Internet of Things generates, I consider the ways in which the Internet of Things is oriented toward enhancing everyday lives, by focusing specifically on the environmental improvements meant to be achieved through these devices. On the one hand, ubiquitous computing has become central to performing new environmental practices such as monitoring environments for pollution, as is the case with citizen sensing. ${ }^{4}$ Within these emerging practices, sensor technologies are also entangled with proposals for new efficiencies to be gained, as well as new opportunities to achieve sustainability through ongoing monitoring of resource use. Yet on the other hand and as will be my focus here, the 
projected rise in computational objects and applications is sure to generate new modalities and distributions of electronic waste.

How do these specific applications and imaginaries of the Internet of Things inform the materialities - and things - that are generated? And what implications do these materialities and things have for media theory and practice? In order to take up these questions, I then discuss how the different approaches to materiality now circulating within media theory and beyond might tune our attention to the thingness of the Internet of Things. I end this chapter by attending to the "The Crystal World" creative-practice project, which materializes a markedly different encounter with digital things. I finally ask how we might further analyze and address the emerging materialities and environmental practices to which ubiquitous computing developments and imaginaries are committing us.

\section{Thingification $=$ Digital Proliferation}

In Digital Rubbish: A Natural History of Electronics, a study on the materiality of digital media focused on electronic waste, I accounted for the many gadgets that have become electronic by providing lists of objects that required special disposal and waste handling upon end-of-life as electronic waste. ${ }^{5}$ The Waste from Electrical and Electronic Equipment (WEEE) directive of the European Commission documents a bewildering array of items - from laptops to toasters - for treatment as a special category of this hazardous waste. ${ }^{6}$ These lists of electronic and electrical waste clearly demonstrate that computation has rapidly spread to numerous gadgets in order to shift and change their functionalities. In this light, it could be argued that toasters and desktop computers share the same space of technomateriality.

Yet, in an early assessment of Digital Rubbish, one reviewer commented that such technologies, even if fitted with electronic capacities, should not be assessed or discussed as computational devices. Why? Because, unlike a computer, a toaster quite obviously does not have storage capacity. However, I would argue here, as I have also done in Digital Rubbish, that digital functionalities are not exclusively located within an object-based architecture of computation, and that computational modalities and distributions may even shift through electronic appliances as banal as toasters and energy monitors. In fact, the WEEE list seems to act as an invitation for further electronicization, containing as it does both electrical and electronic gadgets, thereby suggesting that an iron could as easily be electronic as electrical, that a toaster would 
surely benefit from having a built-in computer and app-ability, and that a refrigerator, too, would have plenty to talk about if it could be wired up with smart communication capabilities.

The proliferation of computational things within the Internet of Things reads as an itemized list of electronic waste in the making. Focusing only on the home within the expanded Internet of Things "ecosystem" (since urban, manufacturing, and logistics applications are also considerable sites for Internet of Things development), we find that the mute and inanimate objects that surround us are steadily learning how to talk through electronic means. From smart toothbrushes to wired dog collars, interconnected coffee machines to alarm clocks, smart energy meters to thermostats, wired-up crockpots to toasters, app-able garage doors to door locks, smart bathroom scales to toilets, networked smoke alarms to security cameras, smart pill boxes to heart rate monitors, data-generating recycling bins to houseplants, networked light bulbs to weather sensors, smart picture frames to glasses, Wi-Fi shopping wands to wearable fertility thermometers, smart bicycle helmets to smart guns, baby sensors to food scanners, smart air monitors to intelligent faucets, talking shoes to plumbing sensors, Bluetooth gloves to tagged key finders, smart luggage to networked egg trays, smart utensils to connected lamps, as well as wireless sleep sensors, smart fire extinguishers, smart irrigation controllers, wearable cameras, and smart bike tires, the things within the Internet of Things consist of a growing list of intelligent devices that would augment, optimize, and interconnect every aspect of our daily lives.

To what extent might this expanding array of digital things generate different modalities, materialities, and environments of computation? While the essential characteristics and operations of computation are often referred back to John von Neumann's computational architecture that encompasses five aspects of input, logic, memory, control, and output (and so the problem of toaster-storage emerges in this context), arguably this proliferation of things is giving rise to different computational diagrams. In this context, sites of storage may shift to USB data loggers and the cloud. Toasters, refrigerators, and energy monitors may have fewer requirements for localized storage and processing, and instead may acquire greater functionality through links to grocery stores, food expiration registries, power plants, and smart grids. While inputs and outputs might still be present in some form, the operations and actors of inputting and outputting may also shift to distinctively nonhuman registers. Computation, then, may occur not only in toasters, but also across multiple 
appliances, networks, and sites, such that the distribution and materiality is configured along much different lines than a discrete PC-type object.

The point here is not merely to attend to the increasing computerization and sensorization of gadgets, but also to focus on the ways in which the Internet of Things and the proliferation of sensors shift the registers, materialities, and environments in and through which we access and experience computation. The Internet of Things works toward the networking and interoperability of objects and infrastructures and, in the process, generates distinct environments and materialities of computation. These are not simply environments as spatial zones or assemblages; even more so, they are environments as emerging conditions by which the Internet of Things is able to control and inform the capacities of and relations to these things, as a distinct technological development. ${ }^{7}$

\section{Thingification by the Billions}

As the above list demonstrates, the vast array of household objects that are currently being transformed into electronic technologies is not only lengthening, but also beginning to constitute a categorically different media "ecosystem." These objects become potentially operative things within the Internet of Things because of RFID tags, sensors, and devices such as smartphones, so that objects may be interacted with, controlled, and even automated to sense and gather data and to carry out programmed and learned functions. The Internet of Things is just as often referred to as the Internet of Everything, since networked and programmed capabilities are meant to inform products, bodies, environments, and systems, where the world is connected through sensors, networks, and a steady flow of data.

The number of devices connected to the Internet is currently estimated to be approximately one and a half to two billion. By 2020, however, this number is forecast to grow to up to fifty billion devices, with many more set to follow. ${ }^{8}$ Billions of things are to be networked, interoperating, and forming new interactions across machines, environments, and people. This promised explosion of interconnected things indicates a shift emerging in the ways in which the Internet operates and things talk and interactions occur, with humans comprising a diminishing portion of Internet traffic. Indeed, while the Internet of Things as a concept is often dated to Mark Weiser's work on ubiquitous computing at Xerox Parc in the 1980s and 1990s, ${ }^{9}$ and as an actual term is dated to $1999,{ }^{10}$ another pivotal moment in the concept's 
elaboration is 2008 , the year when Internet-based machine-to-machine connectivity surpassed that of human-to-human connectivity. ${ }^{11}$

Inevitably, the explosion of things within the Internet of Things is also promised to bring a considerable opportunity for economic development, with the market estimated to be worth between two to fourteen trillion dollars. ${ }^{12}$ Much of this economic potential is meant to be realized through new efficiencies in services, operations, manufacturing, and more. However, economic expansion could also be achieved through the remaking and proliferation of new types of things connected up and made available for new types of interactions - typically at urban and industrial scales, but also through consumer applications. The Consumer Electronics Show in 2014 presented just a small range of some of the new things available for consumption, including an Internet-of-Things-enabled crockpot, controlled by a smartphone, which "puts you in control of your food, which is really exciting." idea that sensors and actuators provide a locus of "control" is a logic that pervades most Internet of Things applications; sensors, networks, and the data they generate are configurations that enable automated exchanges - across people and machines — and may even provide opportunities for control and "new insights," through the ongoing generation and analysis of thing-based data.

In a 2012 presentation on the Internet of Things to the USENIX Association, Google's "chief Internet evangelist," Vint Cerf, discussed the importance of, and growth in, sensor networks and smart things. He noted that it has been "amusing to see the kinds of things that have been connected to the Internet," where gadgets such as an Internet-enabled picture frame at first "sound about as useful as an electric fork." But Cerf admits that these things can actually be "quite handy," as they become controllable through remote or web-based applications so that images may be delivered to picture frames from friends and family, for instance.

Recalling the proverbial toaster reference within computation, Cerf remembered the days when technologists speculated about what it would be like to communicate with your toaster to say "how burned you wanted your toast to be," and that now sensor networks are providing "the ability to remotely manage and observe" any number of thing-based interactions (including burned toast). This alone is important in relation to monitoring and security, Cerf opines, but he draws a further connection to how such a "feedback loop is going to be important from an environmental point of view, because I would say that we don't always understand 
the consequences of our actions." He concludes, "this kind of feedback loop may actually help us do a better job of managing our response to environmental problems including global warming.",14

As with many Internet-of-Things applications, the implicit assumption is that sensor-generated data is needed in order to answer questions and solve problems, including how to be more efficient and how to change behavior through real-time feedback. Smart and sensorized things become sites for realizing new environmental engagements and for encouraging sustainable behavior. "Sustainable media" in this sense involves implementing new electronic infrastructures for controlling environmental systems and problems, and for making the most efficient responses an automatic feature within these networked infrastructures. Ubiquitous computing is thus not only environmental in its spatiality, but also environmental in the way in which it would make these systems sustainable. The sustainability of media here focuses on the proliferation of computing, however, where environments are remade as computational infrastructures and processes.

\section{Thingification as Enabling and Ennobling Technology}

A frequent presentation if not promotion of Internet-of-Things gadgets consists of celebrating the masses of data that will be collected, the new insights that will be gained, and the improvements, often by way of sensor-actuated exchanges, which may be realized through influencing behavior, resource use, and patterns of efficiency. In some cases, this is as basic as "streamlining" experiences so that an alarm clock coordinates timings and talks to a coffee pot in order to ensure coffee is made immediately upon waking. Heating can be set to adjust according to whether one is at home or on the way. Energy meters are one pervasive example of how recurring access to data about energy consumption is meant to influence behavior and bring about a reduction in energy use. Any number of daily practices and relationships become sites where automation and sensor-actuator triggers might "optimize" engagements while influencing behavior. Elsewhere, I refer to this phenomenon as "electronic environmentalism," in order to attend to the ways in which digital technologies have become central to how we identify and act on environmental problems, and offer potential solutions. ${ }^{15}$ The Internet of Things is presented as an enabling and ennobling set of technologies that allow for the seamless 
identification of opportunities to be more parsimonious with resources, for instance, through the sensor-actuator exchanges that intelligent things provide. ${ }^{16}$

Such a logic has pervaded Internet-of-Things prototype and proof-of-concept projects for some time now. A project developed in 2009 through the Senseable City Lab at MIT, “Trash Track," uses this approach by tracking items of trash with electronic tags to provide trash location based on proximity to cellular phone towers. ${ }^{17}$ The far-flung journeys of trash are then mapped in order to understand just how far garbage travels across the United States. Drawing attention to the expanded circuits of how waste travels, the project description notes, "TrashTrack focuses on how pervasive technologies can expose the challenges of waste management and sustainability. Can these same pervasive technologies make $100 \%$ recycling a reality?" 18

Trash Track presents an interesting, if potentially contradictory, example of the drive to use electronics to monitor and act upon environmental problems. Computational exchanges are here the basis for observing, documenting, and so apparently overcoming environmental problems. The project description suggests that by using electronics to focus on the "removal chain"” of waste, there might be realized "a bottom-up approach to managing resources and promoting behavioral change through pervasive technologies." ${ }^{19}$ In many ways, Trash Track plays out the complex contradictions of how electronics become enabling and ennobling devices, while also demonstrating the material and energetic inputs that these technologies require. In other words, what the "Trash Track" project reveals is that the process of mapping trash in order to identify these journeys may be one way of revealing the environmental problem of waste, and yet the documentation of these journeys requires another intensive layer of electronics, communication infrastructures, and computational interfaces to bear environmental witness to the movements of waste. Moreover, the link to how this mapping will enable greater levels of recyclability remains rather unclear, and that which counts as "sustainability" remains within a computational problem space. In an attempt to use electronics as sustainable media tools, a remaking and rematerializing of things occurs that carries additional and specific environmental effects and consequences, often without immediately or obviously addressing the environmental problems that would be solved.

What do things become, in this case, when they are electronically animated to perform resource- and time-saving functions while also enabling environmental 
practices? In what ways do practices of electronic environmentalism, as articulated through the Internet of Things, entangle us within material-political arrangements and practices that require electronics in order to be activated? Thingification presents a considerable (if as-of-yet unaddressed) dilemma in accounting for how sustainability might be articulated through the materialities and exchanges facilitated by the Internet of Things, while also generating new questions about what sorts of things are these?

\section{"Re-thingifying" Media Theory}

As mentioned in my introduction, media theory, as well as a host of other disciplines, has adopted an interest in all things material—or, in other words, has taken a "material turn." At the same time, this attention to materiality often coincides with an interest in "things," in their ability to influence material-political engagements, and even to have a force of their own. From Bruno Latour and his dingpolitik to Jane Bennett and her "vital materialism," as well as the wider developments in new materialism that have emerged as both correctives and supplements to historical materialism, there are now multiple inroads for thinking about and attending to materiality. $^{20}$

This is by no means to conflate these multiple and even diverging approaches to materiality and things, but instead to flag the renewed and ongoing interest in this area. Indeed, given this proliferation of approaches, there arises the very pressing question of how these multiple thing-theories and material philosophies influence our engagements with things when they are as flickering and in process as the Internet of Things. Thingification, to thingify, is a term of possibility and development within Internet of Things sectors: money can be made by connecting things to the Internet. However, within some theoretical arenas to "thingify" has a distinctly different and even pejorative tone, where it suggests an approach that objectifies and reifies (in an historical materialist vein); or an approach that favors things over relations (in a feminist materialism critique). Karen Barad has remarked that "thingification" involves "the turning of relations into 'things,' 'entities,' 'relata,"' and that this "infects much of the way we understand the world and our relationship to it."21 Relations necessarily give rise to things, in Barad's relational ontology, such that to predetermine things is to compromise an attention to, and investment in, how relations and things emerge together. 
From a different perspective, speculative realism has reacted to the privileging of relations as forcing an always-human engagement with things, where things become determined by (typically human) relations. Writings in this area have made the case that things should be allowed to stand alone, even untouched by relations, exuding a thingful integrity. ${ }^{22}$ Within these speculative realist registers, one frequently encounters shimmering poetic lists of things that are seemingly discrete, autonomous, and complete. From fireflies and stones to lightning storms and violets, the lists that speculative realists might assemble provide rather different evocations of things than the smart toothbrushes, vibrators, crockpots, bidets, and baby monitors that litter the gadget world of the Internet of Things. ${ }^{23}$ Here, however, is a no-less quivering but perhaps slightly more sordid world of things that not only are able to talk to and for "us" as consumer-users, but also are able to undertake their own autonomous operations without human interference. In other words, human interaction within the Internet of Things is not a prerequisite for relationality; but relationality does unfold among things, nevertheless.

One could also think of efforts to "follow the thing," where the "social life" of things might be drawn out through the ways in which things circulate and generate distinct social interactions. ${ }^{24}$ Or one could take account of counterproposals that suggest that following the thing is a difficult undertaking when things are in process, falling apart, and generating a complex set of unintended material effects, as things do in the case of electronic waste. ${ }^{25}$ Whichever way you encounter them, electronicized things are not without material-political implication. Rather than attempting to settle a case for or against things, I contend that the way in which particular things are mobilized and animated within the Internet of Things has consequences for the sorts of materiality that are addressed, the processes of materialization that are attended to, and the material relations that are animated or obscured. In this sense, I make the case that the Internet of Things requires us to attend not to one version of materiality, but to many; and to consider how things are never fully formed and fixed objects, but always on the go, generating effects that are never without consequence.

One way of opening up materiality to a proliferation and processual set of encounters is then to ask what "counts" as matter, and often this also means asking what "counts" as the empirical. In what ways are certain registers of thingness apparently given or self-evident? How does the apparent brute facticity of certain things direct our attention to consider materiality in certain ways and not others? If 
products become synonymous with things in the Internet of Things, for instance, how does this influence the very ways in which the givenness of things also assumes an environment where product-things assemble as discrete entities that are always already addressed in their formation as bundled technological and branded objects? In Digital Rubbish, I make the case for addressing electronic waste through a "morethan-empirical" register, and I would suggest a similar proposal for encountering the Internet of Things. ${ }^{26}$ As a mode of materiality, electronic waste is always more than empirical evidence with which to itemize the resources that support and the discards that result from digital technologies. Instead, electronic waste forces us to encounter empiricity and the self-evidence of materiality differently-not just as processes of materialization that might become realized in distinct and disparate places and objects, but also as material politics with specific effects and affective relations. ${ }^{27}$

"More-than," as a strategy, is a way of accounting for things that might also be characterized as radical empiricism, since things can be understood as plural, processual, relational, incomplete, and even as provocations that open into practice. ${ }^{28}$ Things are always more-than-things as immediately encountered. Even the ways in which apparently self-evident things take hold are in themselves tales of material politics, technological arrangements, and environments where thingness remains relatively unquestioned. In other words, a discussion about things should not throw us back into substantialist debates about mind and matter (or derivatives thereof), but rather open up attention to how things come to be, what sustains things, and the effects that things have in the world. This is not an idle philosophical project, but one that has consequences for how relations and things emerge, are mobilized, and transformed. Within the scope of media theory and practice that are increasingly tuned toward material engagements, such an approach also suggests that rethingification does not simply involve mapping out the static stuff that constitutes any particular media technology, but rather requires attending to the ways in which things attract, infect, and propagate mediatized relations, practices, imaginaries, and environments.

\section{"Wondering about Materialism"}

In this more-than-empirical approach to thingly conjugations, new media theories and practices might emerge that involve not ideas applied to matter, not a discursive animation of brute facts, not imaginaries and beliefs as epiphenomena to a more solid 
matter, and not a bifurcation of nature that might even be put back together through various hybridities. And yet, it often seems that which "counts" as empirical research continues to plow the same furrow of self-evident facts or matter that forms objects of study. Instead, and as Isabelle Stengers suggests, we have a need for other kinds of narratives and imaginations, to "make present, vivid and mattering, the imbroglio, perplexity and messiness of a worldly world, a world where we, our ideas and power relations, are not alone, were never alone, will never be alone." 29

Self-evident approaches to materiality can often be strategies of elimination and reduction, Stengers suggests, and it is by encountering materiality in its messiness that we might have cause to "wonder," or in other words, to think about the capacities of things and how they come into formation, how they affect other things, and how they may not simply be doorstops for reason. As Stengers writes,

if there must be a materialist understanding of how, with matter, we get sensitivity, life, memory, consciousness, passions and thought, such an understanding demands an interpretive adventure that must be defended against the authority of whoever claims to stop it in the name of reason. ${ }^{30}$

Stengers suggests that materialism should not be eliminative by merely focusing on the self-evident, but rather that it should connect to "struggle." 31 By considering the apparently self-evident thingness of the Internet of Things, we might then reconsider what sort of thingness is this, what materialities and practices these things commit us to, and what struggles might emerge or be elided in these contexts.

\section{Re-thingifying the Internet of Things}

While the Internet of Things promises to help us achieve greater efficiency and sustainability in many areas of our everyday lives, it then also gives cause to wonder what material entanglements these things generate. While the Internet of Things is meant to continually monitor any number of environmental variables to bring them into a space of data-based management and optimization, these things give cause to wonder about the sorts of environmental awareness and practices that would purportedly be enabled. If we were to move beyond an unproblematic acceptance of the things in the Internet of Things, and begin to ask after how they become things in the first place; or if we were to consider how a forensic tracing of everyday life may 
document some areas for environmental intervention while eliding or overlooking others, then we might be prompted to consider how to re-thingify the Internet of Things: not as an unproblematic proliferation of enabling and ennobling gadgets, but rather as an emerging set of material problems with which we will inevitably have to struggle.

With the Internet of Things, we are involved in the ongoing remaking of materialities that will sediment into new futures. The thingification that occurs through these "systems of systems" articulate distinct material-political processes and relations that could be attended to in any number of ways, from the effects and practices these newly digital things generate, to the resources they require, as well as the deformation and environmental effects they generate at end of life. Here I turn to discuss a creative-practice project, "The Crystal World," which works with computational objects in ways that are at a slant to the Internet of Things, and which engages with the materialities of digital technologies as a way of intervening within other "systems of systems" that electronics generate. Through an analysis of this project, I suggest that the re-thingification of the material trajectories of electronics might be addressed in ways that account for the distributed effects and relations that these technologies create, and also in ways that attend to the possibilities of things to incite new forms of media theory and practice.

\section{The Crystal World}

A somewhat more chemical engagement with computational materiality and minerality, "The Crystal World" was an exhibition and open laboratory developed by Martin Howse, Ryan Jordan, and Jonathan Kemp at the Space White Building in London during the summer of 2012. ${ }^{32}$ This project staged an experimental encounter with the materialities and mineralities of digital technologies, not necessarily as they circulate through markets and homes as functioning electronics, but as they return to the earth at various stages of wasting and residue, whether at end of life or in the process of manufacture.

"The Crystal World" project is a sort of electronic chemistry set in reverse, a cookbook for future fossils, an inquiry into what the life of a chemical-material matrix of electronics is outside of the lab, where the array of substances used for making electronics is apparently without environmental, political, or social effect. The project creators deliberately stage an overflow and menacing bake-off with these materials 
that, in a more sanitized laboratory setting, would appear to be rendered harmless. But this relatively uncontrolled experiment leads one to ask: How do these materials travel in the world? What are their effects? How do they come undone? And how might an attention to these concerns inform the (re) making of electronics in the first place?

Working with the core materials of electronics, the exhibition and laboratory stripped open, broke down, and reworked the gold, silver, plastic, copper, and assorted other minerals that make up electronics. Dipping circuit boards into acid baths and baking off plastic housing from copper electrical cables, the project might on one level seem to have attempted to excavate the most fundamental material substances of electronics. And yet, in this lab/workshop encounter with electronic materialities, the attempt to salvage these minerals opened up into the wider networks and relations that support the material composition of these devices, whether through mining and manufacture; and that repurpose them at end of life, whether through recycling, repair, salvage, or disposal. The ways in which electronics break down play out not simply as a material performance of new fossils in the making, but also as the instantiation of particular material and environmental practices and politics: someone, somewhere, is working through electronics in these ways, and the opening up of these machines is also a way to open up the environmental and material politics that undergird them. ${ }^{33}$

The artists assembled a 540-page The Crystal World Reader as part of the project, which includes a wide range of texts across scientific, philosophical, and artistic fields. As one text collected in The Crystal World Reader, and drawn from the US National Mining Association, remarks, there are at least sixty-six individual minerals that contribute to a typical computer, and "it should be evident that without many minerals, there would be no computers, or televisions for that matter." ${ }^{34}$ This minerality and materiality in the making is not an experience typically made present in our encounters with gadgets. "The Crystal World” front-stages this minerality, where materialities are made, chemical arrangements are strangely crafted, and thingly geologies are transformed through the leakage, sedimentation, and crystallization of computational technologies.

Here, the residue of electronics is transformed into startling forms that are at once fascinating and yet frightening, to the degree to which these strange substances show up as pollutants with lives of their own. The pathways these material 
technologies and chemicals take are not typically sites of human intervention, since they leach through landfills and within recycling sites in so many random and often unseen forms. In "The Crystal World" project and text, these processes of materialization are not only made evident but strangely aestheticized, and yet, this process happens in a way that draws us closer to thinking about the material politics and in/sustainability of electronics, rather than distancing us from them. Given that these artists draw the title for their installation from a J.G. Ballard novel, I am inevitably also drawn to consider yet another artist influenced by Ballard, who was a quintessential thinker and maker of material geologies, Robert Smithson-someone whose writing is also included in their reader. As Smithson has suggested, sediment reveals the often-overlooked aspects of technology. He prefers to think of technology less as "“extensions' of man," and more as "aggregates of elements," or "raw matter of the earth"; he also considers how rust - the apparent decline of technology - is a "fundamental property" of that technology. ${ }^{35}$ As Smithson writes, "rust evokes a fear of disuse, inactivity, entropy, and ruin." These more pervasive conditions of rust, sediment, and grit are the dynamics that run through technology, since "solids are particles built up around flux, they are objective illusions supporting grit, a collection of surfaces ready to be cracked." If, for Bruno Latour, technology is society made durable, then, for Smithson, durability (somewhat perversely) extends to the sediment and recurring remainder that accretes and informs the very life and death of those technologies. ${ }^{36}$

\section{Conclusion}

With the growing electronicization of objects, as well as the emergence of new computational practices and processes, the Internet of Things might soon become integral to new economies and ways of life, as well as to understandings of how environmental practices might be facilitated through ubiquitous computing. An attention to the specific materialities of the Internet of Things brings into focus the entanglements and complexities of our material-media lives and allows for a consideration of how material relations might also influence the emergence of new media-related practices, as well as new media environments.

If we were to extend the logic of "The Crystal World" to the Internet of Things, then we might account for the sediments and remainder of these electronic toasters and intelligent refrigerators in order to gain greater insight into their material 
arrangements and environmental effects. The trajectories and journeys of electronics in their chemical and environmental forms suggest that these materials and things are not neatly contained, but go on to have environmental and health effects that may linger for indefinite time spans. The things that are re-thingifying in this creativepractice provocation open up not just to new things in the making, but also to the new environments that accumulate in and through these things.

The processes of opening up, breaking down, and reworking electronicswhether in overtly material form or otherwise - generate a wider landscape of material relations that cannot be contained within any single device. When computation is thingified, it is also drawing on and establishing distinct material infrastructures and connections. The materialities and things that emerge with, and through, electronic gadgets suggest that from desktop PCs to distributed ubiquitous computing, computation takes place through extended milieus and settles into distinct forms that may very well outlast us. What do these distributed arrangements and materialities of computation enable, what processes and relations do they set in play and require, and what new environmental effects do they generate?

The actual and anticipated debris of electronics might provide one way that we could tune into these material processes to develop practices that speculate about material politics and relations in order to be less extractive and harmful. But this approach would require a re-thingification of things, particularly the Internet of Things. As I have argued here, such a re-thingification would involve attending to the versions of materiality and thingness that are mobilized as political, environmental, and even inventively practical operations. Re-thingification, in this way, would also involve encountering materiality as a process of things and environments becoming together, and of forming particular conjugations and experiences, as well as giving shape to particular material problems and struggles. A critical and material media studies might then begin to develop methods and modes of practice that adopt an experimental set of approaches to re-thingification. These approaches would not necessarily consist of pointing to the brute materiality of electronics — or of simply using electronics to map and describe conditions for behavior change. Instead, they might require the development of practices for engaging with electronic media as environmental and material agents. Re-thingified media practices would then attend to these wider environmental and material effects. 
Re-thingification would further require encountering materiality in multiples, since the thingness of an Internet-of-Things coffee pot and alarm clock interaction might generate significantly different registers of thingness in a factory in China or a mine in Africa. But such re-thingification is not simply about following things, either. This would be to commit our material investigations to forensic tracings primarily, with less attention to possibilities for practice, intervention, and creative realignment. Re-thingifying the Internet of Things is then as much an invitation to reroute these modes of thingly-ness, particularly as they are now forming instructions for environmental practice, as it is a suggestion for questioning what sorts of things are these?

\section{Acknowledgments}

Versions of this chapter have been presented at the "Geologies of Value and Vestige" symposium, Kingston University (2013); the "Media Archaeology and Technological Debris," conference at Goldsmiths, University of London (2013); the "Four by Four" lecture series at the California College of the Arts (2013); and the "When All That Is High-Tech Turns Into Waste" seminar at Lancaster University (2014). The research leading to these results has received funding from the European Research Council under the European Union's Seventh Framework Programme (FP/2007-2013)/ERC Grant Agreement n. 313347, "Citizen Sensing and Environmental Practice: Assessing Participatory Engagements with Environments through Sensor Technologies.”

\section{Notes}

1 See Friedrich Kittler, Gramophone, Film, Typewriter, trans. Geoffrey

Winthrop-Young and Michael Wutz (Stanford, CA: Stanford University Press, 1999); and N. Katherine Hayles, How We Became Posthuman: Virtual Bodies in Cybernetics, Literature, and Informatics (Chicago, IL: Chicago University Press, 1999).

2 See Lisa Parks, "Kinetic Screens: Epistemologies of Movement at the Interface," in MediaSpace: Place, Scale and Culture in a Media Age, edited by Nick Couldry and Anna McCarthy (London: Routledge, 2004), 37-57; Matthew Fuller, Media Ecologies: Materialist Energies in Art and Technoculture (Cambridge, MA: 
MIT Press, 2005); and Jennifer Gabrys, "Media in the Dump," in Trash, edited by John Knechtel (Cambridge. MA: MIT Press, 2006), 156-165.

3 Jennifer Gabrys, "Programming Environments: Environmentality and Citizen Sensing in the Smart City," Environment and Planning D, 32, no. 1 (2014): 30-48.

4 For one example of how sensors are used to test and realize new environmental practices, see the Citizen Sense project at http://www.citizensense.net. 5 Jennifer Gabrys, Digital Rubbish: A Natural History of Electronics (Ann Arbor: University of Michigan Press, 2011).

6 The first 2002 WEEE Directive was put into place in February 2003, and has since been updated to the 2012 Directive. See European Commission, "Directive 2012/19/ EU of the European Parliament and of the Council of 4 July 2012 on Waste Electrical and Electronic Equipment (WEEE) (recast)," Official Journal of the European Union, July 24, 2012, L 197/38. The WEEE directive is accompanied by the RoHS Directive, which restricts certain hazardous substances in electrical and electronic equipment. The first 2002 RoHS Directive was similarly put into place February 2003, and the new RoHS Directive was adopted in January 2013. See European Commission, "Directive 2011/65/EU of the European Parliament and of the Council of 8 June 2011 on the Restriction of the Use of Certain Hazardous Substances in Electrical and Electronic Equipment (recast)," Official Journal of the European Union, July 1, 2011, L 174/88.

7 This argument is taken up more extensively in Jennifer Gabrys, Program Earth: Environmental Sensing Technology and the Making of a Computational Planet (Minneapolis: University of Minnesota Press, 2016).

8 Reporting on a European Commission study in the Internet of Things, the BBC writes, "The commission says that the average person living within the 27nation bloc has at least two devices connected to the net at present - typically a computer and smartphone. It expects the figure to rise to seven by 2015 , with a total of 25 billion wirelessly connected to the net worldwide. By the end of the decade it says that could climb to 50 billion." See "EU Investigates Internet's Spread to More Devices,” BBC News, April 12, 2012, http://www.bbc.co.uk/news/technology17687373 (accessed November 18, 2015).

9 Mark Weiser, “The Computer for the 21st Century," Scientific American, 265, no. 3 (1991): 94-104. 
10 The term is attributed to Kevin Ashton. See "A Brief History of the Internet of Things," Postscapes, http://postscapes.com/internet-of-things-history (accessed November 18, 2015).

11 Dave Evans, "The Internet of Things: How the Next Evolution of the Internet Is Changing Everything," Cisco Whitepaper, April 2011, http://www.cisco.com/web/ about/ac79/docs/innov/IoT_IBSG_0411FINAL.pdf (accessed November 18, 2015). 12 Joseph Bradley, Jeff Loucks, James Macaulay, and Andy Noronha, "Internet of Everything (IoE) Value Index," Cisco Whitepaper, 2013, http://internetofeverything. cisco.com/sites/default/files/docs/en/ioe-valueindex_Whitepaper.pdf (accessed November 18, 2015).

13 “Internet of Things Highlights: 2014 CES," International Consumer Electronics Show (CES), January 9, 2014, http://www.youtube.com/watch?v=tTHqb5RZTVg (accessed November 18, 2015). 14 Vint Cerf, "The Internet of Things and Sensors and Actuators," USENIX Association, March 19, 2013, http://www.youtube.com/watch?v=hIISiYs71Do (accessed November 18, 2015). USENIX is the Advanced Computing Systems Association. See https:// www.usenix.org (accessed November 18, 2015).

15 Jennifer Gabrys, "Powering the Digital: From Energy Ecologies to Electronic Environmentalism," in Media and the Ecological Crisis, edited by Richard Maxwell, Jon Raundalen, and Nina Lager Vestberg (New York, NY: Routledge, 2014), 3-18. 16 For an early, if speculative, example of this, see Bruce Sterling, Shaping Things (Cambridge, MA: Mediawork Pamphlet Series, MIT Press, 2005).

17 Senseable City Lab, "Trash Track” (2009), http://senseable.mit.edu/trashtrack/index. php (accessed November 18, 2015). 18 Ibid.

19 Ibid.

20 For instance, see Bruno Latour, "From Realpolitik to Dingpolitik or How to Make Things Public," in Making Things Public: Atmospheres of Democracy, edited by Bruno Latour and Peter Weibel (Cambridge, MA and Karlsruhe: MIT Press and ZKM, 2005), 14-41; Jane Bennett, Vibrant Matter: A Political Ecology of Things (Durham, NC: Duke University Press, 2010); and Rick Dolphijn and Iris van der Tuin, New Materialism: Interviews \& Cartographies (Ann Arbor: University of Michigan Library, Open Humanities Press, 2012). 
21 Karen Barad, "Posthumanist Performativity: Toward an Understanding of How Matter Comes to Matter," Signs, 28, no. 3 (2003): 812.

22 For an overview of these speculative realist approaches, see Levi Bryant, Nick Srnicek and Graham Harman (eds.), The Speculative Turn: Continental Materialism and Realism (Melbourne: re.press, 2011).

23 An exception to this is the "Object Lessons" series edited by Ian Bogost and Chris Schaberg. See http://objectsobjectsobjects.com (accessed November 18, 2015). 24 Arjun Appadurai, "Introduction: Commodities and the Politics of Value," in The Social Life of Things: Commodities in Cultural Perspective (Cambridge: Cambridge University Press, 1986), 3-63.

25 Gabrys, Digital Rubbish, 74-98, 127-143. 26 Ibid., 3-4.

27 For an expanded discussion on material politics, see Jennifer Gabrys, Gay Hawkins and Mike Michael, eds., Accumulation: The Material Politics of Plastic (London: Routledge, 2013).

28 In this condensed list, I am drawing on Adrian Mackenzie's discussion of radical empiricism and things, and he is further informed by William James and Elizabeth Grosz. See Mackenzie, Wirelessness: Radical Empiricism in Network Cultures (Cambridge, MA: MIT Press, 2010); James, Essays in Radical Empiricism (Lincoln: University of Nebraska Press, 1996 [1912]); and Grosz, Time Travels: Feminism, Nature, Power (Durham, NC: Duke University Press, 2005).

29 Isabelle Stengers, "Wondering about Materialism," in The Speculative Turn, 371. 30 Ibid., 372 .

31 Ibid. For an expanded discussion on this point of encountering materiality through “diverging” approaches, see Jennifer Gabrys, "A Cosmopolitics of Energy: Diverging Materialities and Hesitating Practices," Environment and Planning A, 46, no. 9 (2014): 2095-2109.

32 Martin Howse, Ryan Jordan and Jonathan Kemp, “The Crystal World” (2012), http:// crystal.xxn.org.uk/wiki/doku.php?id=the_crystal_world:space:opening (accessed November 18, 2015).

33 Martin Howse and Jonathan Kemp, "The Crystal World," Mute, September 26, 2012, http://www.metamute.org/editorial/articles/crystal-world (accessed November 18, 2015). For a discussion of electronics as fossils, see Gabrys, Digital Rubbish. 
34 National Mining Association, "Minerals in Typical Computers," in The Crystal World Reader and Manual of Speculative Apparatus, edited by Anonymous (January 2012), 137.

35 Robert Smithson, The Collected Writings of Robert Smithson, edited by Jack Flam (Berkeley: University of California Press, 1996), 17.

36 Smithson, The Collected Writings, 100-107; and Bruno Latour, "Technology is Society Made Durable," in A Sociology of Monsters: Essays on Power, Technology and Domination, edited by John Law (London: Routledge, 1991), 103-131. 